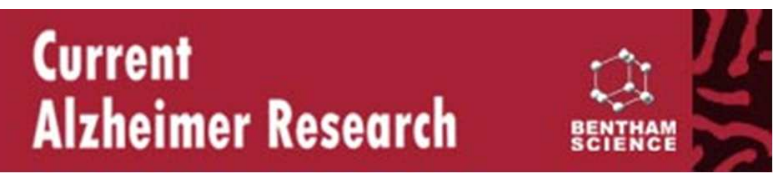

\title{
Abnormal clock gene expression and locomotor activity rhythms in two month-old female APPSwe/PS1dE9 mice.
}

\begin{tabular}{|r|l|}
\hline Journal: & Current Alzheimer Research \\
\hline Manuscript ID & CAR-2016-0093.R1 \\
\hline Manuscript Type: & Original Article \\
\hline Date Submitted by the Author: & n/a \\
\hline Complete List of Authors: & $\begin{array}{l}\text { Oyegbami, Olaide; University of Nottingham, School of Psychology } \\
\text { Collins, Hilary; University of Nottingham, School of Pharmacy } \\
\text { Pardon, Marie-Christine; University of Nottingham, School of Life Sciences } \\
\text { Ebling, Francis; University of Nottingham, School of Life Sciences } \\
\text { Heery, David; University of Nottingham, School of Pharmacy } \\
\text { Moran, Paula; University of Nottingham, School of Psychology }\end{array}$ \\
\hline Keywords: & $\begin{array}{l}\text { Alzheimer's Disease, circadian, clock genes, APPSwe/PS1 mice, Per1, Per2, } \\
\text { Cry1, Cry2 }\end{array}$ \\
\hline &
\end{tabular}


2

3

4

5

6

7

8

9

10

Olaide Oyegbami ${ }^{1,2}$, Hilary M Collins ${ }^{2}$, Marie C Pardon ${ }^{3}$, Fran JP Ebling ${ }^{3}$, David M Heery ${ }^{2}$, Paula M Moran*1

(1) School of Psychology, University of Nottingham, Nottingham NG7 2RD United Kingdom.

(2) School of Pharmacy, University of Nottingham, Nottingham NG7 2Rd United Kingdom.

(3) School of Life Sciences, Queens Medical Centre, University of Nottingham, Nottingham NG7 2UH, United Kingdom

*Correspondence to: Dr. Paula Moran, School of Psychology, University of Nottingham, Nottingham NG7 2RD, U.K.

Tel: +44 1159515312

Fax: +44 1159515324

Email: paula.moran@nottingham.ac.uk

Running Title : Altered circadian rhythms in young APPSwe/PS1dE9 mice 


\begin{abstract}
In addition to cognitive decline, Alzheimer's disease (AD) is also characterized by agitation and disruptions in activity and sleep. These symptoms typically occur in the evening or at night and have been referred to as 'sundowning'. These symptoms are especially difficult for carers and there are no specific drug treatments. There is increasing evidence that these symptoms reflect an underlying pathology of circadian rhythm generation and transmission. We investigated whether a transgenic mouse model relevant to $\mathrm{AD}$ (APPswe/PS1dE9) exhibits circadian alterations in locomotor activity and expression of clock genes involved in the regulation of the circadian cycle. Female mice at 2 months of age were investigated in their home cage. Results show that the APPswe/PS1dE9 transgene alters levels and patterns in circadian rhythm of locomotor activity. Expression of the clock genes Per1, Per2, Cry1 and Cry2 was found to increase at night compared to day in wild-type control mice in the medulla/pons. This effect was blunted for Cry1 and Cry2 gene expression in APPswe/PS1dE9. In summary, this study suggests altered circadian regulation of locomotor activity is abnormal in female APPswe/PS1dE9 mice and that this alteration has biomolecular analogies in a widely available model of AD. Furthermore, the early age at which these effects are manifest suggests that these circadian effects may precede plaque development. The APPswe/PS1dE9 mouse genetic model may have potential to serve as a tool in understanding the neuropathology of circadian abnormalities in $\mathrm{AD}$ and as a model system to test novel therapeutic agents for these symptoms.
\end{abstract}

Key words:

Alzheimer's Disease, circadian, clock genes, APPswe/PS1dE9 mice, Per1, Per2, Cry1, Cry2, Bmal, Rev-Erb $\square$, Rev-Erb $\beta$ 
Introduction

Alzheimer's Disease (AD) is associated with behavioural disturbances such as restlessness and agitation that are exacerbated in late afternoon or early evening, sometimes referred to as "sundowning". The day/night rhythmicity of these symptoms has led to the suggestion that disturbances in the biological clock may underly them. This is supported by both behavioural and molecular evidence [for reviews see $(1,2)]$. Behaviourally, patients with AD have been shown to have lower locomotor activity during the day and a higher percentage of their total daily activity at night relative to age-matched comparison subjects. The activity rhythms of AD patients have been reported to delayed by four hours in AD patients compared to normal elderly controls (3-5) AD patients also show less inter-daily stability (a measure of rhythmicity) and a later acrophase (time at which a peak of activity occurs $)(3,6)$. Circadian rhythms are regulated by a master clock located in the suprachiasmatic nucleus (SCN) $(7,8)$. Recently Videnovic et al., (1) showed in a small post-mortem sample of patients with AD and age-matched controls that SCN neuronal number correlated with the amplitude of the circadian rhythm of locomotor activity.Identification of neural and non-neural tissues that contain the molecular machinery required for the generation of endogenous rhythms has been made possible by the identification of clock genes (7). These genes include Clock, Bmal1, Per1, Per2, Per3, Cry1, Cry2, Rev-Erb $\square$, Rev-Erb $\beta$, Rora, Rorb and Rorc (9). Through binding to E-box elements, Clock:Bmall heterodimers drive the expression of multiple Clockcontrolled genes (CCGs). As the Per and Cry protein products accumulate in the cytoplasm, they dimerize and translocate to the nucleus to inhibit the activity of Clock:Bmal1, thereby inhibiting their own transcription. Reverb $\alpha$ forms an additional negative loop to the cycle by inhibiting Bmall transcription. As a positive loop, Per proteins inhibit Rev-erb $\square$ transcription; this lifts the Rev-erb $\square$ mediated inhibition of Bmal1 transcription, which serves to activate the system (10). It has now been established that individual cells possess self-sustained circadian oscillators and are not simply weak "slave" oscillators driven by the master SCN clock (11). The discovery of SCN-independent brain clocks in a number of areas in the mammalian brain including the olfactory bulb, brainstem and hippocampus suggests that the mammalian circadian system involves multiple pacemaking nuclei $(12,13)$. Little is known about the role of the relationship between extra SCN brain oscillators and rhythmic and circadian behavior and even less is known about whether there may be alterations in these oscillators that might play a role in rhythmic and circadian abnormalities in AD. It is notable that the hippocampus and olfactory bulb brain regions have been associated with the earliest stages of AD pathology (14). 
In order to address these questions, a number of studies have investigated whether genetic mouse models relevant to AD show circadian abnormalities in their behavioral activity patterns in addition to their known cognitive abnormalities. Conclusions in mouse models have been mixed. Most studies [though not all, see (15)] have shown a generalised hyperactivity in $\mathrm{AD}$ mouse models with some studies showing this to be specific to nocturnal activity $(16,17)$ and some to diurnal activity $(18,19)$. This variability is unsurprising given that studies differ in the transgenic model used (e.g. Tg2576, APPSwe/PS1dE9, APP23), background strain of mouse (e.g. C57BL/6, CD1/129) and method used to assess activity (e.g. running wheel vs. home cage). Differences in the age at testing and whether studies have been carried out under free running vs entraining light-dark conditions also contribute to the variability in inferred phenotypes $(20,21)(22-24)$. While the number of studies is as yet small, many do indicate some modest circadian abnormality when compared to wild-type controls that show greater consistency.

Several studies using different measurement techniques have shown that clock gene expression (mostly Per1 and Per2) varies across the 24 hour cycle in the $\operatorname{SCN}$ in mice $(25,26)$ and more recently in rats $(27)$. Wang et al., (28) showed that Per2 mRNA and protein expression varied across the 24 hour cycle in the hippocampus. While these rhythms are altered with normal ageing in several species including mice, hamsters and rats (2931), few studies have investigated whether these expression patterns are altered in genetic mouse models relevant to AD. Duncan and colleagues (32) showed the clock gene Per2 is increased at night in the SCN of wild-type mice with a strong trend towards attenuation of this increase in APPXPS1 mice that did not reach statistical significance. The mice used in that study were on a CD1/129 background strain and notably did not show the hyperactivity frequently reported in APPXPS1 mice. The WT mice in that aspect of the study were also 15 months old, and as the study indicated age-associated reductions in activity rhythms it is possible that a floor effect may have masked potential changes associated with genotype for the baseline day/night changes in Per2. 
In the current study we investigated whether the 24 hour rhythm of home cage activity is abnormal in APPSwe/PS1dE9 mice on the more common C57BL/6J background strain. We subsequently investigated whether these mice concomitantly show abnormalities in differential mRNA expression of a number of clock genes between the highest and lowest point of their activity in the 24 hour cycle; Zeitgeber times (ZT) 2 and 14 (day vs. night). Zeitgeber times were defined in relation to the light-dark cycle with ZT0 as lights on and LT12 as lights off. We focused on brain regions outside of the SCN: the hippocampus (important for memory function) and the medulla/pons (important for the sleep-wake cycle).

\section{MATERIALS AND METHODS}

Animals and housing conditions

The mice used in these studies were the double transgenic AD mouse model, APPswe/PS1dE9 and WT controls of the same C57/BL6 genetic background. A chimeric mouse/human APP695 with mutations linked to familial $\mathrm{AD}$ (APPSwe) was expressed as well as a mutation in the human PS1 gene carrying the exon-9-deleted variant associated with $\mathrm{AD}(33,34)$. All experimental animals used in the present work were bred in the University of Nottingham's transgenic animal facility and have been described previously $(35,36)$. Prior to activity monitoring studies, all mice were housed in the same room, maintained on a light/dark (LD) light cycle, with lights on at 07:00 hrs. Room temperature, relative humidity and air exchange were automatically controlled. Mice were housed in individually ventilated cages (Tecniplast, Buguggiate (VA), Italy) with a floor area $501 \mathrm{~cm}$, dimensions (WxDXH) 391X199x160 mm. Cages had a play tunnel and shredded paper nesting material. They were housed in groups of 2-3 with ad libitum access to food and water, and provided with nesting material and a play tube. During the studies, the animals were singly-housed and were subjected to either a LD cycle or constant dim red light (“darkness": DD). All experiments were approved by the University of Nottingham Animal Welfare and Ethical Review Board and were carried out in compliance with the Home Office regulations on animal experimentation with appropriate personal and project license authority under the Animals (Scientific Procedures) Act, UK 1986. After locomotor activity recording, mice were euthanized under LD conditions at ZT2 (day) and ZT14 (night) time points. These were selected on the basis of the highest and lowest activity peaks. There were $\mathrm{n}=3$ WT and $\mathrm{n}=4$ APPswe/PS1dE9 per time point. The hippocampus and medulla/pons regions were dissected and snap frozen on dry ice and stored at $-80^{\circ} \mathrm{C}$ prior to analysis. 
Experimentally naïve 2 month-old female mice were used, 8 APPSwe/PS1dE9 transgenic mice and 6 wild-type (WT) littermates. Mice were tested in staggered cohorts following breeding to ensure that each mouse was the same age at the beginning of behavioural testing.

\section{Home-cage activity}

Activity recording occurred in identical boxes, sized $16 \mathrm{~cm}$ x $19 \mathrm{~cm}$ x $26 \mathrm{~cm}$. There were four boxes per lighttight chamber, size; $80 \mathrm{~cm}$ x $61 \mathrm{~cm}$ x 71cm (ENV- 018, MED associates Inc., St Albans, VT, U.S.A.). Each chamber contained a fluorescent bulb (170 lux) and red bulb (8 lux) which supplied white light during the day and red light at night respectively (as appropriate to the experiment). Employing a camera at the roof of the chamber, the Video Tracking Interface software (Version 1, MED associates inc) maintained the current tracking location of each individual mouse and recorded the footage from each individual box. This footage was then converted into distance travelled (in $\mathrm{cm}$ ), stereotypic counts and ambulatory counts by the Activity Monitor software (Version 5, MED Associates Inc.). Each chamber also contained a fan, mounted at the back to provide air exchange and background noise $(55 \mathrm{~dB})$.

Experiment 1: In the initial period of the study, the mice were under a 12h light: $12 \mathrm{~h}$ dark cycle (lights on 07:00 hrs ZT12 lights off 19:00 ZT24) and locomotor activity was recorded for 6 days (8640 mins). Locomotor activity recording in DD for 24 days followed immediately, the mice remained in the experimental room, the fluorescent lights were turned off and red lights kept on permanently, the chamber doors were closed and a radio was permanently switched on which provided additional background noise $(70 \mathrm{~dB})$. This was done to ensure the elimination of all photic and non-photic cues associated with the building. At the end of the experiment, the mice were re-housed with their original littermates and returned to the holding room.

\section{$\underline{\text { Analysis of locomotor activity data }}$}

The locomotor activity data was collected in 1 minute bins and several variables extracted and analyzed. For the purposes of this study, Diurnal distance was defined as activity that occurred in the light phase (07:00-19:00 hrs), Nocturnal activity was defined as activity that occurred in the dark phase (19.00 - 07:00 hrs). Percentage of nocturnal activity refers to the percentage of total daily activity occurring during the nocturnal period (6). Percentage of the first/last 2 hours in the light/dark period refers to the percentage of total daily activity occurring in the first/last 2 hours of the light/dark phases (32). Period length was calculated using the $\mathrm{Chi}^{2}$ periodogram analysis (37). Period is defined as the time elapsed for one complete oscillation or cycle (the distance in time between two consecutive peaks [or troughs] of a recurring wave and was calculated using Chi2- 
periodogram analysis (37) . Period length under free-running conditions (DD) was calculated by visually fitting a line to the activity onsets, estimating the total phase shift over the course of the study, then calculating the mean shift per cycle. This was done by an experimenter who was blind to the genotype of the mice. Cosinor analysis fits a cosine wave to the raw data (37). This yields the mesor (central point of the fitted cosinor function), amplitude (height of the fitted cosine curve), relative amplitude (amplitude/mesor) and acrophase (31). The software used is available at http://www.circadian.org/softwar.html. Acrophase is the time at which the peak of a rhythm occurs. It refers to the phase angle of the peak of a cosine wave fitted to the raw data of a rhythm. The unit of measurement is degrees $\left(^{\circ}\right)$ which is converted to a value proportional to that of a 24-hour clock using the formula, $H=(D \times 24) / 360+S$, where $D$ is the value in degrees, $H$ is the value in hours, and $S$ is the start time. Robustness has been described as how regular a circadian rhythm is and calculated as the percentage of the total variance that can be accounted for by the cosine wave (a measure of rhythmicity). Essentially the robustness statistic reflects the extent of stationarity of a rhythm, a calculation of the periodograms Qp value compared to the Qp value associated with a perfectly rhythmic time series.(38) The Rhythmicity Index measured the strength of the rhythm calculated as the height of the third peak in an autocorrelation analysis (39).

Activity Onset was determined as the first time-point from 6hrs before lights off where activity counts exceeded the $24 \mathrm{hrs}$ mean and remained sustained over three of the following bins. This is dissociable from the onset of the active phase. Activity Offset was determined as the latest time-point with three of the previous bins also above the $24 \mathrm{hrs}$ (23). This is dissociable from the end of the active phase. Activity Duration was calculated as the difference between Activity Onset and Activity Offset.

Under LD conditions, lights on was $07.00 \mathrm{hrs}$ and lights off was $19.00 \mathrm{hrs}$. Mice are largely nocturnal and onset of the active phase is closely linked to lights off. However, as a result of the changes to onset/offset of the active phase under DD conditions and the fact that there are individual differences in the amount and direction of these shifts, onset and offset of the active phase can no longer be fixed to 07.00 and 19.00 hrs respectively and rhythms would be expected to free-run. This therefore means diurnal activity, nocturnal activity, percentage of activity at night and percentage of the first/last 2 hours in the light/dark period cannot be measured. Double plotted actograms were used to visually represent each day in DD (37).

The number of total stereotypic counts (repeated movement within a specified area around the mouses location detected by the software) made by the mice was also recorded. Diurnal/ nocturnal stereotypic counts were 
obtained from this measure. Data reflected activity counts very closely hence overall effects are referred to but the data is not reported.

qRT-PCR

Clock gene expression in dissected brain regions was determined by qRT-PCR. Total RNA was extracted from tissue using TRIzol (Sigma). RNA (500ng) was reverse transcribed using oligo(dT)12-18, and quantitative RTPCR was performed on a Mx3005P cycler (Stratagene) using Brilliant II SYBR green qPCR mix (Agilent Technologies). Values were normalized to expression levels of the housekeeping gene, GAPDH. The relative differences among the comparison groups were calculated using the $\Delta \Delta \mathrm{CT}$ method. Primer sequences used for qPCR detection of mouse genes were as follows:

$\begin{array}{ll}\text { mPer1 forward } & \text { 5'-TCGAAACCAGGACACCTTCTCT-3' } \\ \text { mPer1 reverse } & \text { 5'-GGGCACCCCGAAACACA-3', } \\ \text { mPer2 forward } & \text { 5'-GCTCGCCATCCACAAGAAG-3' } \\ \text { mPer2 reverse } & \text { 5'-GCGGAATCGAATGGGAGAATA-3' } \\ \text { mClock forward } & \text { 5'-CGGCGAGAACTTGGCATT-3' } \\ \text { mClock reverse } & \text { 5'-AGGAGTTGGGCTGTGATCA-3' } \\ \text { mBmall forward } & \text { 5'-TGACCCTCATGGAAGGTTAGAA-3' } \\ \text { mBmal1 reverse } & \text { 5'-GGACATTGCATTGCATGTTGG-3', } \\ \text { mCry1 forward } & \text { 5'-ATCGTGCGCATTTCACATAC-3' } \\ \text { mCry1 reverse } & \text { 5'-TCCGCCATTGAGTTCTATGAT-3', } \\ \text { mCry2 forward } & \text { 5'CCATTATGAAGATGGCCAAGGA-3' } \\ \text { mCry2 reverse } & \text { 5'-CTGCCCATTCAGTTCGATGATT-3', } \\ \text { Rev-erb } \square \text { forward } & \text { 5'-TGGCATGGTGCTACTGTGTAAGG-3' } \\ \text { Rev-erb } \square \text { reverse } & \text { 5'-ATATTCTGTTGGATGCTCCGGCG-3', } \\ \text { Rev-erb } \square \text { forward } & \text { 5'-GGAGTTCATGCTTGTGAAGGCTGT-3' } \\ \text { Rev-erb } \square \text { reverse } & \text { 5'-CAGACACTTCTTAAAGCGGCACTG-3'. }\end{array}$

\section{Statistics}

Statistics were performed using SPSS (Version 18, 2009 SPSS Inc. Chicago, Illinois, USA). For activity data one-way analysis of variance (ANOVA) was used with genotype (WT Vs APPswe) as independent variable. For LD Vs DD comparisons repeated measures ANOVA was used with lighting condition (LD Vs DD) as independent variable. 
In mRNA gene expression experiments two-way ANOVA was used with Zeitgeber time (ZT2 Vs ZT14) and Genotype (WT Vs APPswe) as independent variables. T-tests were used for individual comparisons.

\section{RESULTS}

\section{Locomotor Activity : LD conditions}

Figure 1A shows that in 12L:12D conditions APPSwe/PS1dE9mice ('APPswe' in Figure) were significantly more hyperactive than WT mice $[\mathrm{F}(1,12)=6.369, \mathrm{p}=0.027]$, they were also more active at night than WT mice $[\mathrm{F}(1,12)=8.107, \mathrm{p}=0.015]$, and had a greater percentage of activity at night compared to WT mice $[F(1,12)=19.575, p=0.001]$. They were not significantly more active in the day, though as is typical in mice absolute activity was low during this period $[\mathrm{F}(1,12)=1.529, \mathrm{p}=0.240]$.

In exploring the patterns of activity across the 24 hour period, APPSwe/PS1dE9 mice showed significantly less activity in the first 2 hours in the light period compared to WT mice $[F(1,12)=10.225 p=0.008]$ as well in the last 2 hours in the light period $[\mathrm{F}(1,12)=4.936 \mathrm{p}=0.046]$ (Figure 2A-2B). In the dark phase, APPSwe/PS1dE9 mice had more activity than WT mice in the first 2 hours $[F(1,12)=17.975 p=0.001]$ and significantly less than WT mice in the last 2 hours of the dark phase $F(1,12)=20.392 p=0.001$ ] (Figure 2C-2D). Stereotypic counts did not differ between APPSwe/PS1dE9 and WT mice on any of these measures (data not shown).

Robustness, was also found to be significantly higher in APPSwe mice $[\mathrm{F}(1,12)=8.53 \mathrm{p}=0.013]$ (Figure 3A) while rhythmicity index was unaltered in APPSwe/PS1dE9 mice $[\mathrm{F}(1,12)=0.397, \mathrm{p}=0.541]$ (Figure 3B). The time of peak activity (acrophase) occurred earlier in APPSwe/PS1dE9 mice than in wild-type controls $[F(1,12)=7.723 \mathrm{p}=0.017]$ (Figure 3C). Relative amplitude was also significantly higher in APPSwe/PS1dE9 mice $[F(1,12)=19.723, \quad p=0.001]$ (Figure 3D). Period length in APPSwe/PS1dE9 mice did not differ significantly from that of WT mice $[\mathrm{F}(1,12)=0.094, \mathrm{p}=0.764]$ (Figure 4).

\section{Locomotor activity: DD conditions}

In DD conditions APPSwe/PS1dE9 mice were also significantly more active that WT mice $[\mathrm{F}(1,12)=8.689$, $\mathrm{p}=0.012$ ] (Figure 1B). Also in common with mice in LD conditions, APPSwe/PS1dE9 mice showed significantly higher robustness than their WT counterparts $[F(1,12)=5.457, p=0.038]$ (Figure 3A) while rhythmicity index remained unaltered $[\mathrm{F}(1,12)=1.397, \mathrm{p}=0.260]$ (Figure 3B). Higher relative amplitude in APPSwe/PS1dE9 mice was seen $[F(1,12)=7.768, p=0.016]$ (Figure 3D), while activity offset was significantly 
earlier in AppSwe/Ps1dE9 mice $[\mathrm{F} 1,12=16.01, \mathrm{P}<0.001]$ (Figure 3E), while activity duration was not significantly different between genotypes (Figure 3F). Also similarly to LD conditions, the time of peak activity (acrophase) in APPSwe/PS1dE9 mice was significantly earlier in APPSwe/PS1dE9 mice $[\mathrm{F}(1,12)=16.648$, $\mathrm{p}=0.002]$ (Figure 3C). The length of the free-running period was significantly shorter in APPSwe/PS1dE9 mice $[F(5,7)=5.36, p<0.05]$ (Figure 4B);

The length of the free-running period was significantly shorter in APPSwe/PS1dE9 mice $[F(1,12)=5.36$, $\mathrm{p}<0.05]$ (Figure 4B); Mean and standard error of the mean period length WT $(24.37 \pm 0.07)$ and APPSwe/PS1dE9 (24.2 \pm 0.02$)$. Calculation of period length by chi2 periodogram (37) produced similar estimates of period length (WT 24.28 \pm 0.07 vs APPSwe/PS1dE9 24.2 \pm 0.03 ).

\section{Comparing LD to DD conditions}

In all activity measures, there were significant effects of lighting condition (LD vs DD) on robustness, rhythmicity index and acrophase but no interactions with genotype on any measure. The effect of lighting conditions on total activity did not differ between WT and APPSwe/PS1dE9 mice, $[\mathrm{F}(1,12)=0.029, \mathrm{p}=0.868]$ (data not shown) nor on relative amplitude $[\mathrm{F}(1,12)=0.617, \mathrm{p}=0.447]$. Compared to $\mathrm{LD}$, the activity rhythms of mice were significantly less robust in $\mathrm{DD}[\mathrm{F}(1,12)=15.351, \mathrm{p}=0.002]$ (Figure 3A) but rhythmicity index was significantly increased in $\mathrm{DD}[\mathrm{F}(1,12)=27.511, \mathrm{p}=0.000]$ (Figure 3B). The time of peak activity (acrophase) was also significantly earlier in DD compared to $\mathrm{LD}$ conditions, $[\mathrm{F}(1,12)=56.153, \mathrm{p}=0.000]$ and overall in APPSwe/PS1dE9 mice compared to WT mice $[F(1,12)=20.493, p=0.001]$ (Figure 3C).

\section{Clock Gene Expression}

\section{Effect of genotype}

Expression levels of mRNA for 8 clock genes were investigated in two brain regions (hippocampus and medulla/pons) of wild-type and APPSwe/PS1dE9 mice at ZT2 and ZT14. A significant main effect of genotype on Cry1 $(p=0.038)$ and Cry2 $(p=0.035)$ was observed in the medulla/pons (Figure 5B).No significant effect of genotype was seen in the hippocampus. There were significant interactions between genotype and time of day (outlined below).

Effect of time of day 
In the hippocampus (Figure 5A) there was a general trend towards higher expression at ZT14 compared to ZT2, these levels reached significance for the Per1 ( $\mathrm{p}=0.048)$ Per2 $(\mathrm{p}=0.032)$ and Rev-erb $\square(\mathrm{p}=0.041)$ expression. In the medulla/pons (Figure 5B), there was similarly a general trend towards higher expression at ZT14 compared to ZT2 these levels reaching significance for Per1 $(\mathrm{p}=0.006)$, Per $2(\mathrm{p}=0.023)$, Cry1 $(\mathrm{p}=0.008)$ and Cry2 $(\mathrm{p}=0.003)$.

\section{Genotype $\mathbf{x}$ time of day interaction}

In the medulla/pons, the effect of TOD on the expression of Cry1 $(p=0.04)$, Cry2 $(p=0.042)$, Clock $(p=0.025)$ and Bmal1 ( $\mathrm{p}=0.018)$ was significantly different in WT mice and APPSwe/PS1dE9 mice. In APPSwe/PS1dE9 mice, there was a significant down-regulation of Cry1 $(p=0.045)$, Cry2 $(p=0.03)$, Clock $(p=0.05)$ and Bmal1 $(\mathrm{p}=0.03)$ gene expression at ZT14 compared to WT mice at ZT14.

\section{DISCUSSION}

These data indicate that APPSwe/PS1dE9 mice show locomotor hyperactivity, a finding consistent with a number of previous studies $(23,40-42)$. This hyperactivity was manifest particularly at night as expected in nocturnal animals. The hyperactivity in APPSwe/PS1dE9 relative to WT controls was observed in both LD and free running (DD) conditions.

A number of alterations in the circadian pattern of activity of APPSwe/Ps1dE9 mice were detected across several parameters of rhythmicity. Most notably, APPSwe/Ps1dE9 mice showed shorter period length, increased robustness, an earlier acrophase. When mice were switched from LD to DD conditions, the mean activity onset of WT mice was delayed by approximately 2.5 hours while in APPSwe/PS1dE9 mice it remained unchanged. There was also a delay in mean activity offset (approximately $4 \mathrm{hrs)}$ observed in WT mice that is not observed in APPSwe/PS1dE9 mice. The onset and offset of the active phase in nocturnal species are closely coincident with light onset and offset (32). When mice were switched from LD to DD conditions, WT mice showed a clear phase delay while APPSwe/PS1dE9 mice maintained their prior rhythm. This is possibly linked to the shorter period length in APPSwe/PS1dE9 mice. The period length for the APPSwe/PS1dE9 is approximately $0.1-0.15$ hours shorter than that for the WT mice. Therefore, after 25 days in DD, there is at least a 2.5 hour difference in the time of activity onset between the two groups. Period length under constant environmental conditions (i.e., DD) is a fundamental parameter of the circadian timing system. Because the APPSwe/PS1dE9 mice have a period that is closer to 24 hours, their rhythms remain closer to the original LD 
cycle and clock-time than those of the WT mice (see Figure 4A for illustration). These indices taken together suggest abnormality in the circadian timing system in APPSwe/PS1dE9 mice. Shorter period length is reminiscent of effects found in several studies showing that period length shortens with age in many animal species (43-45). This may be consistent with an accelerated aging effect in APPSwe/PS1dE9 mice. We did not however see the generalised fragmented circadian activity pattern frequently reported in studies in older mice e.g., (46). There are some studies both in humans and mice that report a lengthening of the circadian period with age (47). Methodological considerations have been highlighted as contributing to these variable findings including after-effects from the former LD conditions (46).

Studies of patients with Alzheimer's Disease suggest increased activity at the end of the active phase (48), however it is clear that there is large individual variation in this pattern. In the present study while we found increased activity it is concentrated at the earlier rather than later part of the active phase. A shorter period length maybe a contributory factor to this effect. Clinical studies also show later acrophase in Alzheimer's patients while these mice show earlier acrophase. However direct transposition between behavioural endpoints in human clinical studies and those in mice must be drawn with caution. In patients the studies are necessarily carried out in LD conditions and there is considerable heterogeneity in age, diagnosis and sex. The present study was carried out in female mice only, while most patient studies include both sexes. One advantage of mouse models for examining questions abot circadian biology is that they can be carried out easily in free running conditions thereby assessing the endogenous free running rhythm. We have preliminary evidence from this study for a shortening of period length in DD conditions, which might suggest a potential mechanism to investigate in patient studies. For example further addressing the question of mechanism of circadian disruption in patients it would be of interest to investigate whether period length is shorter under LD conditions specifically in females.

Robustness of the circadian rhythm was significantly altered in DD compared to LD, resulting in the mice having a less robust rhythm in DD. However, RI (rhythmicity index) was unchanged under DD conditions. Although robustness and RI both measure the presence and strength of the rhythm, they address different aspects. In robustness, a single cosine curve is fitted on to a mean of the days measured and gives the variance that can be accounted for by this curve. In RI, an autocorrelation comparison of elements within a series (i.e. across days) is performed. Thus, a high value of robustness refers to variance within the mean $24 \mathrm{~h}$ period i.e. it is a smooth rhythm with minimal noise. APPSwe/PS1dE9 mice showed increased robustness of their activity 
rhythm compared to WT but no differences in RI value, suggesting a smoother rhythm within $24 \mathrm{~h}$ periods measured for APPSwe/PS1dE9 mice but similar consistency between genotypes across days.

Abnormality of the circadian system at the behavioural level is potentially supported by gene expression studies. Increases in clock gene expression at night (ZT14) versus day (ZT2) were found in mice sacrificed under LD conditions in both the hippocampus and the medulla/pons regions in these mice. This increase extends previous studies conducted in the SCN region of this strain of mice (32), and further indicates that changes in clock gene expression can be detected in multiple brain regions.

In APPSwe/PS1dE9 mice the ZT14 increase was blunted for Cry1 and Cry2 genes. Kume et al., (49) showed that mCRY1 and mCRY2 are potent inhibitors of CLOCK:BMAL1-mediated transcription. All of the four genes implicated in this loop of transcription regulation are differentially expressed in the medulla/pons at ZT14 in 2 months old APPSwe/PS1dE9 mice compared to WT mice at ZT14. Previous studies have shown that the medulla and pons play a critical role in promoting wakefulness $(50,51)$. Patients with Alzheimer's disease suffer from a disrupted sleep-wake cycle $(6,52,53)$. It is possible that there is an association between these findings and the disrupted sleep-wake cycle observed in AD. Besides their role in directly inhibiting CLOCK:BMAL1-mediated transcription, (54), the mCRY proteins play a critical role in the translocation of mPER1 and mPER2 proteins from the cytoplasm to the nucleus (49).

In terms of the general effect of time of day (TOD), our study demonstrates that there was an increase in expression of Per1, Per2 and Rev-erb $\square$ in the hippocampus at ZT14 compared to ZT2. We have also observed an increase in gene expression levels of Per1, Per2, Cry1 and Cry2 at ZT14 compared to ZT2 in the medulla/pons. Somewhat contrastingly, studies by (28) showed that peak expression of Per2 in the hippocampus was found between ZT23 and ZT2 while lowest expression was at ZT10. (12) showed that Per2 expression in the dentate gyrus, CA1 and CA3 sub-regions of the hippocampus peak at ZT22, ZT21.5 and ZT23.5 respectively in rats. It is difficult to make direct comparisons as the rodent species, age, method of expression measurement, time-point and brain tissue sampling technique differs from the present study. The study by (32) found a significant upregulation of Per2 expression in the SCN at ZT10 compared to ZT2 in APPSwe/PS1dE9 mice, which agrees with our findings in WT mice only. One crucial difference from the present study is a different background strain of mouse [c57BL/6 vs CD1/129]. Given that the WT expression patterns are similar between day and night between the studies, and differ in the effects of the transgene, epistatic effects of the transgene cannot be ruled out. 
There was no effect of genotype on any of the clock genes investigated in the hippocampus. Similarly, (32) found that Per2 expression in the hippocampus, cingulate cortex and motor cortex were not significantly affected by genotype or time of day. The overall expression level of clock genes relative to GAPDH was significantly lower in the hippocampus compared to the medulla/pons, which may have made it more difficult to detect changes, however we did show a clear day/night increase for Per1, Per2 and Rev-erb $\square$. An increase in Per2 at night has recently been shown in a similar background strain and has been shown to be compromised by A $\square$ 31-35 peptide delivered directly into the hippocampus (55). An increase in Rev-erb $\square$ in the hippocampus at night replicates findings from (56) who showed this effect for both mRNA expression and protein levels in the hippocampus in WT mice of a similar background strain. This suggests these are robust effects. One limitation of the dissection technique we used is that we do not differentiate subregions with differing projection regions and functions. Thus, it is possible that while we could detect relatively large effects in the medulla/pons region, subtle effects in some hippocampal subregions or cell types in APPSwe/PS1dE9 might be more difficult to detect using this approach. One further limitation of the present study is that we were only able to assess two time points throughout the $24 \mathrm{hr}$ period. While we ensured to select points corresponding to the lowest and highest activity peaks, wider effects could be missed. Equally expression levels of different genes such as Clock and Bmal may have different rhythms in different tissues as has been suggested previously, the same time point may not be appropriate for all genes measured $(29,57)$. In the light of these limitations, null results for any given gene or tissue in this study must be interpreted with caution.

Many studies have shown day-night rhythmicity of clock genes. For e.g. Harbour et al., (12) analysing Per2 expression in 20 forebrain areas showed that peak expression of Per2 immunoreactive cells in the SCN occurred in the early part of the dark phase, at ZT 14.25. Using transgenic rats expressing the firefly luciferase gene under the control of the mouse Per1 promoter, (25) investigated the intrinsic rhythmicity of Per1 in isolated brain regions. 14 out of 27 Per1 expressing regions were found to be rhythmic. Peak Per1 bioluminescence in the extra-SCN regions was in the dusk and at night while that in the SCN was in the day. This is consistent with our findings of a night-time increase although (25) failed to show intrinsic rhythmicity in the hippocampus, median (MR) and dorsal (DR) raphe, substantia nigra (SN) and ventral tegmental area (VTA) regions of the midbrain.

Using siRNA-mediated gene dosage analysis, (58) showed that expression of clock genes responds to genetic perturbations in a compensatory manner. For example, they found that Cry2 was upregulated proportionally when Cryl was knocked down in a dose-dependent manner. Also, down regulation of Bmal1 by 
siRNA revealed that its immediate downstream effector, Rev-erb $\square$, was also downregulated, subsequently increasing the expression of Per2. It is likely that a disruption of clock gene expression rhythms in a specific brain region has a corresponding effect in the function of that region. For instance, in AD patients, there is a loss of diurnal rhythmic expression of hBmall, hCryl and hPerl in the pineal gland (which secretes melatonin) of both preclinical (Braak stages I-II) and clinical AD subjects (Braak stages V-VI) (59). This loss of clock gene rhythmicity in the pineal gland is associated with a dramatic decrease in nocturnal melatonin concentrations as well as a loss of the circadian rhythm in melatonin production $(60,61)$.

The APPSwe/PS1dE9 mice used in the present experiment were tested at 2 months of age. Typically these mice display $\mathrm{A} \beta$ deposition by 4 months with the appearance of plaques from 6 up to 12 months accompanied by concomitant increase of $A \beta$ levels. Behavioural deficits such as memory deficits typically manifest at 5-6 months of age $(35,62,63)$. This suggests that the effects we may not be consequent to amyloid plaques. One pathology that has been described for these mice at a similarly young age is abnormal long-term potentiation, a neuronal phenomenon proposed to be a synaptic index of learning (64) but not seen in all studies (65). Increased levels of oligomeric $A \beta$ have been observed in young "pre-plaque" mice of a similar age (PND60), while neurogenesis in the dentate gyrus area of the hippocampus has been also been shown to be reduced in APPSwe/dE9 mice $(65)$. Busche et al $(66,67)$ showed in an APP/PS1 AD mouse model that plaque formation is preceded by specific neural hyperactivity (in these experiments in the hippocampus) possibly via a soluble $\mathrm{A} \square$ mechanism. These changes may be of interest to explore in the context of the behavioural changes we report, as they are detectable at an age that has consistently been shown to be prior to plaque pathology or profound memory deficits. Our unpublished preliminary data for 9month APPSwe/PS1dE9 males suggest that the behavioural abnormalities we report here are also seen in males at an older age suggesting the effect persists beyond that at which amyloid plaque deposition occurs.

The present study was carried out in female mice only. Whether these results generalise to young males remains to be investigated. Sex differences have been reported for APPSwe/dE9 mice in the amount of A $\beta$ deposited though this has been measured at 4 months of age (68) or across a range of ages [2-5 months] (69). At 4 months of age, females show higher levels of $A \beta 40$ and $A \beta 42$ in the hippocampus (68). This might explain why we have been able to detect such early behavioural changes compared to prior studies that have used mixed sex cohorts.

Our data taken together suggest that female APPSwe/PS1dE9 mice have early ( 2 months of age) circadian abnormalities in home-cage locomotor activity rhythms and blunted day to night increases in the clock 
genes Cry1 and Cry2 in the medulla/pons. These findings merit further investigation in the context of understanding how AD pathology leads to gene expression and behavioural symptoms related to "sundowning".

\section{Figure Legends}

Figure 1: Mean distance travelled over a 24 hour period in 2 month old female WT and APPSwe/PS1dE9 (APPSwe) mice under (A) LD conditions (mean of 6 days) and (B) constant darkness (DD) conditions (mean of 24 days).

Figure 2: Effect of genotype on mean activity as a percentage of total activity during first 2 hrs in light phase (A), last 2 hrs in light phase (B), first 2 hrs in dark phase (C) and last 2 hrs in dark phase (D) in a study of 2 months old APPSwe mice under LD conditions. There was a significant effect $(\mathrm{p}<0.05)$ of genotype on all four measures.

Figure 3: Effect of genotype on (A) Robustness, (B) Rhythmicity index (C) Acrophase (D) relative amplitude (E) activity offset (F) activity duration in LD and DD conditions. ${ }^{*} \mathrm{p}<0.05 * * \mathrm{p}<0.01 * * * \mathrm{P}<0.001$ versus wildtype (WT) in same light condition. \#p $<0.05 \# \# p<0.01 \# \# \# p<0.001 \# \# \# p<0.0001$ main effect of light condition i.e. Light-dark (LD) Vs constant darkness (DD).

Figure 4: (A) Double - plotted actograms illustrating delay in onset of active phase in WT moved to DD but not in APPSwe/PS1dE9 mice (red lines indicate line fitting to activity onset). (B) mean period length (+/- standard error of the mean) in DD.

Figure 5: Day(ZT2) /night (ZT14) expression of core clock genes in the hippocampus (A) and medulla/pons (B) WT/ZT2 (n=3), WT/ZT14 (n=3), APPSwe/PS1dE9/ZT2 (n=4), APPSwe/PS1dE9/ZT14 (n=4). Values shown are mean (biological replicates) \pm S.E with WT/ZT 2 normalized to $100 \%$. * indicates a significant overall effect of ZT (day Vs night) $\mathrm{p}<0.05$, ANOVA). \#indicates a significant genotype X ZT interaction ( $<<0.05$ ANOVA).

References 
1. Videnovic A, Lazar AS, Barker RA, Overeem S. 'The clocks that time us'--circadian rhythms in neurodegenerative disorders. Nat Rev Neurol. 2014;10(12):683-93.

2. Musiek ES, Xiong DD, Holtzman DM. Sleep, circadian rhythms, and the pathogenesis of Alzheimer disease. Exp Mol Med. 2015;47:e148.

3. Satlin A, Volicer L, Stopa EG, Harper D. Circadian locomotor activity and core-body temperature rhythms in Alzheimer's disease. Neurobiology of Aging. 1995;16(5):765-71.

4. Harper DG, Stopa EG, McKee AC, Satlin A, Harlan PC, Goldstein R, et al. Differential circadian rhythm disturbances in men with Alzheimer disease and frontotemporal degeneration. Arch Gen Psychiatry. 2001;58(4):353-60.

5. Harper DG, Volicer L, Stopa EG, McKee AC, Nitta M, Satlin A. Disturbance of endogenous circadian rhythm in aging and Alzheimer disease. Am J Geriatr Psychiatry. 2005;13(5):359-68.

6. Volicer L, Harper D, Manning B, Goldstein R, Satlin A. Sundowning and Circadian Rhythms in Alzheimer's Disease. Am J Psychiatry. 2001;158(5):704-11.

7. Guilding C, Piggins HD. Challenging the omnipotence of the suprachiasmatic timekeeper: are circadian oscillators present throughout the mammalian brain? European J Neurosci. 2007;25(11):3195-216.

8. Reppert, Weaver. Coordination of circadian timing in mammals. Nature. 2002;418(6901):935-41.

9. Barnard AR, Nolan PM. When Clocks Go Bad: Neurobehavioural Consequences of Disrupted Circadian Timing. PLoS Genet. 2008;4(5):e1000040.

10. Preitner N, Damiola F, Luis Lopez M, Zakany J, Duboule D, Albrecht U, et al. The Orphan Nuclear Receptor REV-ERBÎ \pm Controls Circadian Transcription within the Positive Limb of the Mammalian Circadian Oscillator. Cell. 2002;110(2):251-60.

11. Nagoshi E, Saini C, Bauer C, Laroche T, Naef F, Schibler U. Circadian Gene Expression in Individual Fibroblasts: Cell-Autonomous and Self-Sustained Oscillators Pass Time to Daughter Cells. Cell. 2004;119(5):693-705.

12. Harbour VL, Weigl Y, Robinson B, Amir S. Comprehensive Mapping of Regional Expression of the Clock Protein PERIOD2 in Rat Forebrain across the 24-h Day. PLoS ONE. 2013;8(10):e76391.

13. Abe M, Herzog ED, Yamazaki S, Straume M, Tei H, Sakaki Y, et al. Circadian rhythms in isolated brain regions. J Neurosci. 2002;22(1):350-6.

14. Stratmann K, Heinsen H, Korf HW, Del Turco D, Ghebremedhin E, Seidel K, et al. Precortical Phase of Alzheimer's Disease (AD)-Related Tau Cytoskeletal Pathology. Brain Pathol. 2016;26(3):371-86.

15. Duncan MJ, Smith JT, Franklin KM, Beckett TL, Murphy MP, St Clair DK, et al. Effects of aging and genotype on circadian rhythms, sleep, and clock gene expression in APPxPS1 knock-in mice, a model for Alzheimer's disease. Experimental neurology. 2012;236(2):249-58.

16. Van Dam D, D'Hooge R, Staufenbiel M, Van Ginneken C, Van Meir F, De Deyn PP. Age-dependent cognitive decline in the APP23 model precedes amyloid deposition. Eur J Neurosci. 2003;17(2):388-96.

17. Huitron-Resendiz S, Sanchez-Alavez M, Gallegos R, Berg G, Crawford E, Giacchino JL, et al. Ageindependent and age-related deficits in visuospatial learning, sleep-wake states, thermoregulation and motor activity in PDAPP mice. Brain Res. 2002;928(1-2):126-37.

18. Sterniczuk R, Dyck RH, LaFerla FM, Antle MC. Characterization of the 3xTg-AD mouse model of Alzheimer's disease: Part 1. Circadian changes. Brain Res. 2010;1348:139-48.

19. Pugh PL, Richardson JC, Bate ST, Upton N, Sunter D. Non-cognitive behaviours in an APP/PS1 transgenic model of Alzheimer's disease. Behav Brain Res. 2007;178(1):18-28.

20. Van-Dam D, D'Hooge R, Staufenbiel M, VanGinneken C, VanMeir F, DeDeyn PP. Age-dependent cognitive decline in the APP23 model precedes amyloid deposition. European Journal of Neuroscience. 2003;17(2):388-96.

21. Pugh et al. Non-cognitive behaviours in an APP/PS1 transgenic model of Alzheimer's disease. Behavioural Brain Research. 2007;178(1):18-28. 
22. Bano-Otalora B, Popovic N, Gambini J, Popovic M, Vina J, Bonet-Costa V, et al. Circadian System Functionality, Hippocampal Oxidative Stress, and Spatial Memory in the APPswe/PS1dE9 Transgenic Model of Alzheimer Disease: Effects of Melatonin or Ramelteon

. Chronobiol Int. 2012;29:822-34.

23. Gorman MR, Yellon S. Lifespan daily locomotor activity rhythms in a mouse model of amyloidinduced neuropathology

. Chronobiol Int. 2010;27(6):1159-77.

24. Sterniczuk R, Dyck RH, LaFerla FM, Antle MC. Characterization of the 3xTg-AD mouse model of Alzheimer's disease: Part 1. Circadian changes. Brain Research. 2010;1348(0):139-48.

25. Abe M, Herzog ED, Yamazaki S, Straume M, Tei H, Sakaki Y, et al. Circadian rhythms in isolated brain regions. 2002(1529-2401 (Electronic)).

26. Ono D, Honma K, Honma S. Circadian and ultradian rhythms of clock gene expression in the suprachiasmatic nucleus of freely moving mice. Sci Rep. 2015;5:12310.

27. Yamaguchi Y, Okada K, Mizuno T, Ota T, Yamada H, Doi M, et al. Real-Time Recording of Circadian Per1 and Per2 Expression in the Suprachiasmatic Nucleus of Freely Moving Rats. J Biol Rhythms.

2016;31(1):108-11.

28. Wang LMC, Dragich JM, Kudo T, Odom IH, Welsh DK, O'Dell TJ, et al. Expression of the circadian clock gene Period2 in the hippocampus: possible implications for synaptic plasticity and learned behaviour. ASN NEURO. 2009;1(3):e00012.

29. Wyse CA, Coogan AN. Impact of aging on diurnal expression patterns of CLOCK and BMAL1 in the mouse brain. Brain Res. 2010;1337:21-31.

30. Duncan MJ, Prochot JR, Cook DH, Tyler Smith J, Franklin KM. Influence of aging on Bmall and Per2 expression in extra-SCN oscillators in hamster brain. Brain Res. 2013;1491:44-53.

31. Chun LE, Woodruff ER, Morton S, Hinds LR, Spencer RL. Variations in Phase and Amplitude of Rhythmic Clock Gene Expression across Prefrontal Cortex, Hippocampus, Amygdala, and Hypothalamic Paraventricular and Suprachiasmatic Nuclei of Male and Female Rats. J Biol Rhythms. 2015;30(5):417-36.

32. Duncan MJ, Smith JT, Franklin KM, Beckett TL, Murphy MP, Clair DKS, et al. Effects of aging and genotype on circadian rhythms, sleep, and clock gene expression in APPxPS1 knock-in mice, a model for Alzheimer's disease. Experimental Neurology. 2012;236(2):249-58.

33. Jankowsky JL, Slunt HH, Ratovitski T, Jenkins NA, Copeland NG, Borchelt DR. Co-expression of multiple transgenes in mouse CNS: a comparison of strategies. Biomolecular Engineering. 2001;17(6):157-65.

34. Savonenko A, Xu GM, Melnikova T, Morton JL, Gonzales V, Wong MP, et al. Episodic-like memory deficits in the APPswe/PS1dE9 mouse model of Alzheimer's disease: relationships to beta-amyloid deposition and neurotransmitter abnormalities. Neurobiol Dis. 2005;18(3):602-17.

35. Bonardi C, de Pulford F, Jennings D, Pardon MC. A detailed analysis of the early context extinction deficits seen in APPswe/PS1dE9 female mice and their relevance to preclinical Alzheimer's disease. Behav Brain Res. 2011;222(1):89-97.

36. Maroof N, Ravipati S, Pardon MC, Barrett DA, Kendall DA. Reductions in Endocannabinoid Levels and Enhanced Coupling of Cannabinoid Receptors in the Striatum are Accompanied by Cognitive Impairments in the A beta PPswe/PS1 Delta E9 Mouse Model of Alzheimer's Disease. J Alzheimers Dis. 2014;42(1):227-45.

37. Refinetti R, Cornélissen, G., and Halberg, F. Procedures for numerical analysis of circadian rhythms. . Biological Rhythm Research. 2007;38:275-325.

38. Refinetti R. Non-stationary time series and the robustness of circadian rhythms. Journal of Theoretical Biology. 2004;227:571-81.

39. Levine JD, Funes P, Dowse HB, Hall JC. Signal analysis of behavioral and molecular cycles. BMC Neurosci 2002;3(1).

40. Huitrón-Reséndiz S, Sánchez-Alavez M, Gallegos R, Berg G, Crawford E, Giacchino JL, et al. Ageindependent and age-related deficits in visuospatial learning, sleep-wake states, thermoregulation and motor activity in PDAPP mice. 2002(0006-8993 (Print)). 
41. Vloeberghs E, Dam DV, Engelborghs S, Nagels G, Staufenbiel M, Deyn PPD. Altered circadian locomotor activity in APP23 mice: a model for BPSD disturbances. European Journal of Neuroscience. 2004;20(10):2757-66.

42. Ambrée O, Touma C, Görtz N, Keyvani K, Paulus W, Palme R, et al. Activity changes and marked stereotypic behavior precede A pathology in TgCRND8 Alzheimer mice. Neurobiology of Aging. 2006;27(7):955-64.

43. Pittendrigh CS, Daan S. Functional-Analysis of Circadian Pacemakers in Nocturnal Rodents .4. Entrainment - Pacemaker as Clock. J Comp Physiol. 1976;106(3):291-331.

44. Morin LP. Age-Related-Changes in Hamster Circadian Period, Entrainment, and Rhythm Splitting. Journal of Biological Rhythms. 1988;3(3):237-48.

45. Witting W, Mirmiran M, Bos NPA, Swaab DF. The Effect of Old-Age on the Free-Running Period of Circadian-Rhythms in Rat. Chronobiology International. 1994;11(2):103-12.

46. Welsh DK, Richardson GS, Dement WC. Effect of Age on the Circadian Pattern of Sleep and Wakefulness in the Mouse. J Gerontol. 1986;41(5):579-86.

47. Valentinuzzi VS, Scarbrough K, Takahashi JS, Turek FW. Effects of aging on the circadian rhythm of wheel-running activity in C57BL/6 mice. Am J Physiol. 1997;273(6 Pt 2):R1957-64.

48. Volicer L, Harper DG, Manning BC, Goldstein R, Satlin A. Sundowning and circadian rhythms in Alzheimer's disease. Am J Psychiatry. 2001;158(5):704-11.

49. Kume K, Zylka MJ, Sriram S, Shearman LP, Weaver DR, Jin X, et al. mCRY1 and mCRY2 are essential components of the negative limb of the circadian clock feedback loop. Cell. 1999;98(2):193-205.

50. Chen C, Kuo T, Hsieh I, Yang C. Electrical stimulation of the rostral ventrolateral medulla promotes wakefulness in rats. Sleep Medicine. 2013;14(11):1076-84.

51. Kalauzi A, Spasic S, Petrovic J, Ciric J, J S. Cortico-pontine theta carrier frequency phase shift across sleep/wake states following monoaminergic lesion in rat. 2012;31:163-71.

52. Bliwise DL, Carroll JS, Lee KA, Nekich JC, Dement WC. Sleep and "sundowning" in nursing home patients with dementia. Psychiatry Research. 1993;48(3):277-92.

53. Nowak L, Davis JE. A Qualitative Examination of the Phenomenon of Sundowning. Journal of Nursing Scholarship. 2007;39(3):256-8.

54. Etchegaray JP, Lee C, Wade PA, Reppert SM. Rhythmic histone acetylation underlies transcription in the mammalian circadian clock. Nature. 2003;421(6919):177-82.

55. Wang X, Wang L, Yu Q, Xu Y, Zhang L, Zhao X, et al. Alterations in the expression of Per1 and Per2 induced by Abeta31-35 in the suprachiasmatic nucleus, hippocampus, and heart of C57BL/6 mouse. Brain Res. 2016;1642:51-8.

56. Valnegri P, Khelfaoui M, Dorseuil O, Bassani S, Lagneaux C, Gianfelice A, et al. A circadian clock in hippocampus is regulated by interaction between oligophrenin-1 and Rev-erb alpha. Nature Neuroscience. 2011;14(10):1293-U108.

57. Kaneko $\mathrm{K}$, Yamada $\mathrm{T}$, Tsukita $\mathrm{S}$, Takahashi $\mathrm{K}$, Ishigaki $\mathrm{Y}$, Oka $\mathrm{Y}$, et al. Obesity alters circadian expressions of molecular clock genes in the brainstem. Brain Res. 2009;1263:58-68.

58. Baggs JE, Price TS, DiTacchio L, Panda S, FitzGerald GA, Hogenesch JB. Network Features of the Mammalian Circadian Clock. PLoS Biol. 2009;7(3):e1000052.

59. Wu Y-H, Fischer DF, Kalsbeek A, Garidou-Boof M-L, van der Vliet J, van Heijningen C, et al. Pineal clock gene oscillation is disturbed in Alzheimer's disease, due to functional disconnection from the "master clock". The FASEB Journal. 2006;20(11):1874-6.

60. Liu R-Y, Zhou J-N, van Heerikhuize J, Hofman MA, Swaab DF. Decreased Melatonin Levels in Postmortem Cerebrospinal Fluid in Relation to Aging, Alzheimer's Disease, and Apolipoprotein E-epsilon4/4 genotype. The Journal of Clinical Endocrinology \& Metabolism. 1999;84(1):323-7.

61. Skene DJ, Vivien-Roels B, Sparks DL, Hunsaker JC, PÃ@vet P, Ravid D, et al. Daily variation in the concentration of melatonin and 5-methoxytryptophol in the human pineal gland: effect of age and Alzheimer's disease. Brain Research. 1990;528(1):170-4. 
62. Jankowsky JL, Fadale DJ, Anderson J, Xu GM, Gonzales V, Jenkins NA, et al. Mutant presenilins specifically elevate the levels of the 42 residue B-amyloid peptide in vivo: evidence for augmentation of a 42specific Gamma-secretase. Human Molecular Genetics. 2004;13(2):159-70.

63. Garcia-Alloza M, Robbins EM, Zhang-Nunes SX, Purcell SM, Betensky RA, Raju S, et al. Characterization of amyloid deposition in the APPswe/PS1dE9 mouse model of Alzheimer disease. Neurobiology of Disease. 2006;24(3):516-24.

64. Volianskis A, Kostner R, Molgaard M, Hass S, Jensen MS. Episodic memory deficits are not related to altered glutamatergic synaptic transmission and plasticity in the CA1 hippocampus of the APPswe/PS1deltaE9deleted transgenic mice model of ss-amyloidosis. Neurobiol Aging. 2010;31(7):1173-87.

65. Hu YS, Xu P, Pigino G, Brady ST, Larson J, Lazarov O. Complex environment experience rescues impaired neurogenesis, enhances synaptic plasticity, and attenuates neuropathology in familial Alzheimer's disease-linked APPswe/PS1 Delta E9 mice. Faseb J. 2010;24(6):1667-81.

66. Busche MA, Eichhoff G, Adelsberger H, Abramowski D, Wiederhold KH, Haass C, et al. Clusters of hyperactive neurons near amyloid plaques in a mouse model of Alzheimer's disease. Science. 2008;321(5896):1686-9.

67. Busche MA, Chen XW, Henning HA, Reichwald J, Staufenbiel M, Sakmann B, et al. Critical role of soluble amyloid-beta for early hippocampal hyperactivity in a mouse model of Alzheimer's disease. Proceedings of the National Academy of Sciences of the United States of America. 2012;109(22):8740-5.

68. Wang J, Tanila H, Puolivali J, Kadish I, van Groen T. Gender differences in the amount and deposition of amyloid beta in APPswe and PS1 double transgenic mice. Neurobiology of Disease. 2003;14(3):318-27.

69. Pistell PJ, Zhu M, Ingram DK. Acquisition of conditioned taste aversion is impaired in the amyloid precursor protein/presenilin 1 mouse model of Alzheimer's disease. Neuroscience. 2008;152(3):594-600. 
Figure 1

A

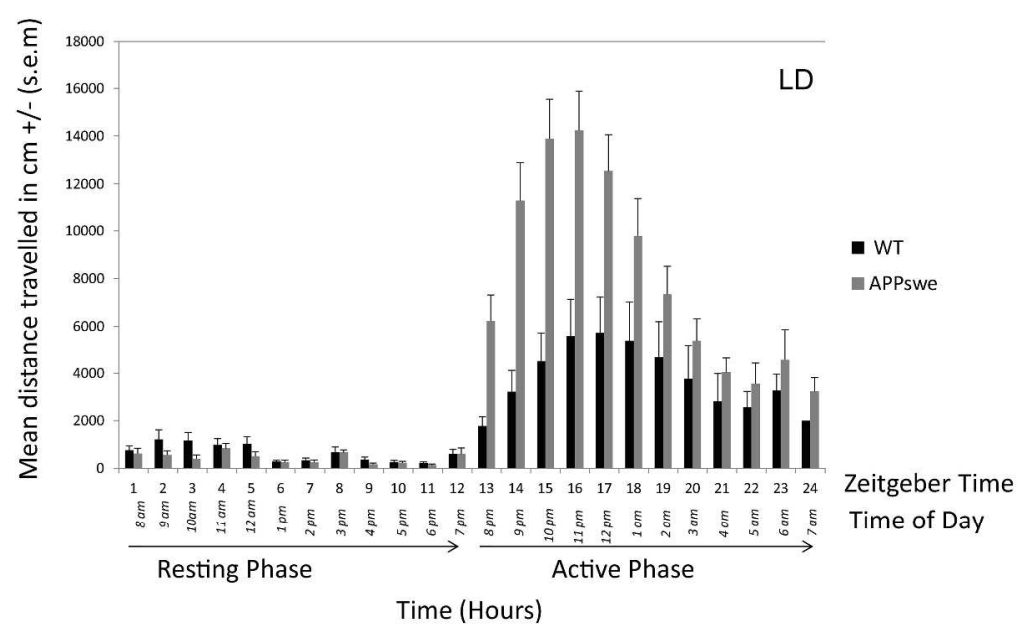

B
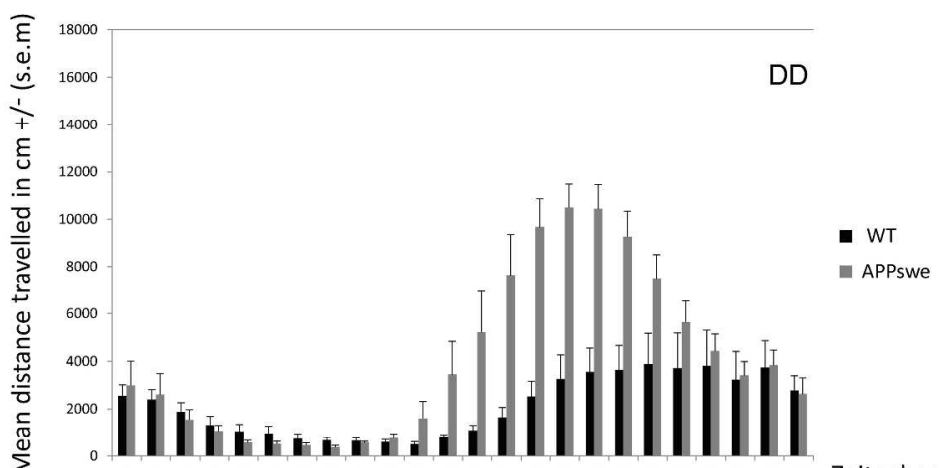

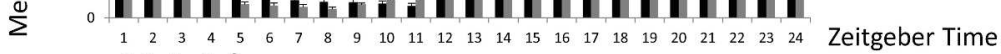

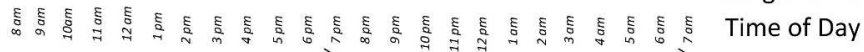

Resting Phase Active Phase Time (Hours)

Figure 1: Mean distance travelled over a 24 hour period in 2 month old female WT and APPSwe/PS1dE9 (APPSwe) mice under (A) LD conditions (mean of 6 days) and (B) constant darkness (DD) conditions (mean of 24 days).

Figure 1 $276 \times 384 \mathrm{~mm}(300 \times 300$ DPI $)$ 
Figure 2

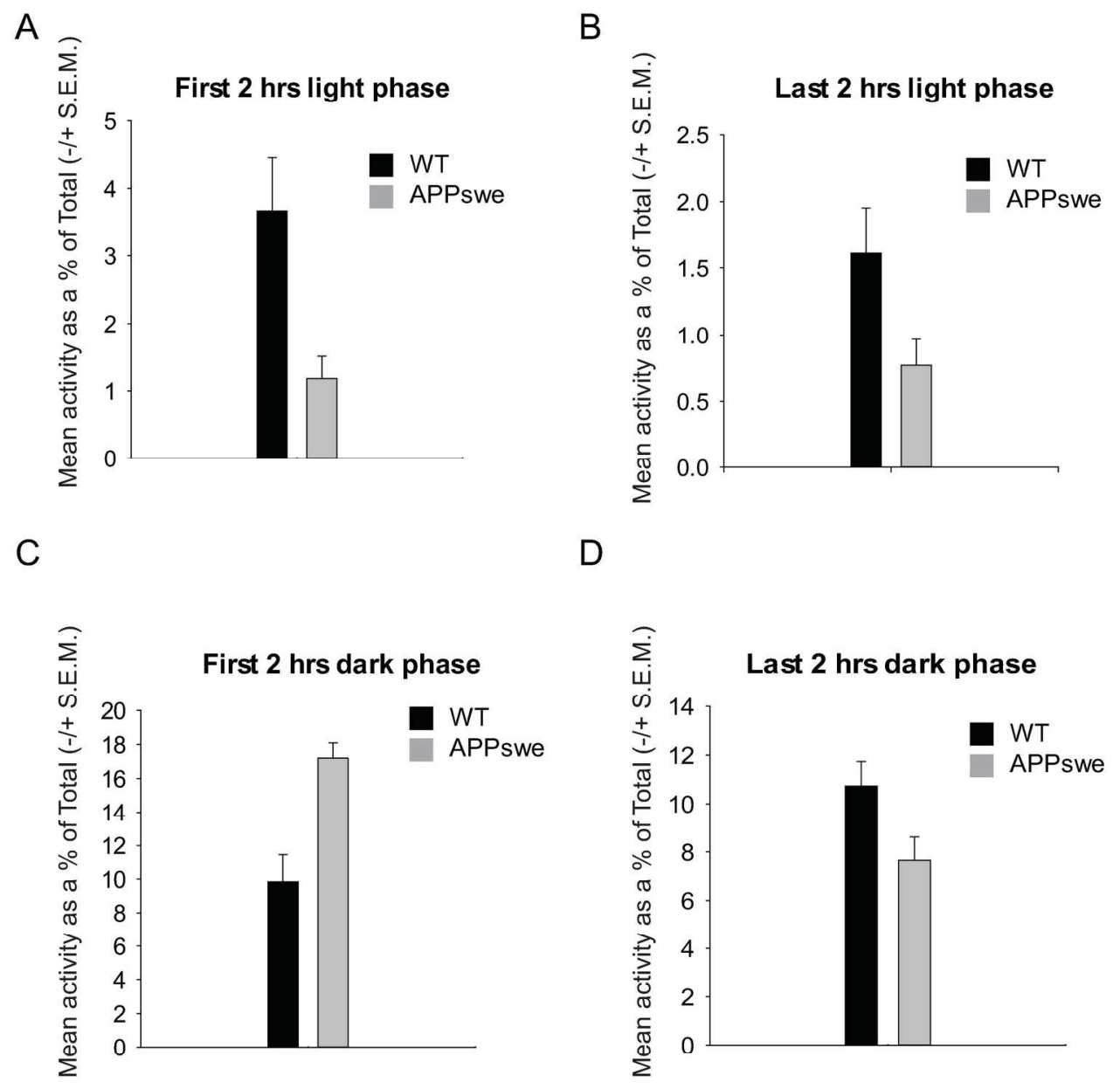

Figure 2: Effect of genotype on mean activity as a percentage of total activity during first 2 hrs in light phase (A), last 2 hrs in light phase (B), first 2 hrs in dark phase (C) and last 2 hrs in dark phase (D) in a study of 2 months old APPSwe mice under LD conditions. There was a significant effect $(p<0.05)$ of genotype on all four measures.

Figure 2

$184 \times 212 \mathrm{~mm}(300 \times 300 \mathrm{DPI})$ 
Figure 3

A

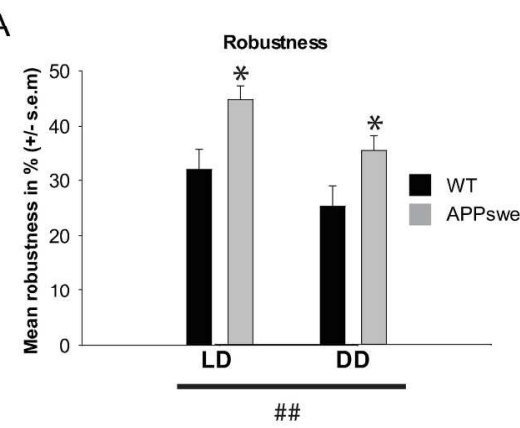

C

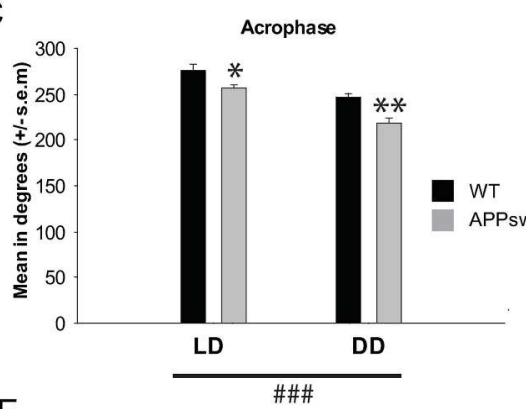

E

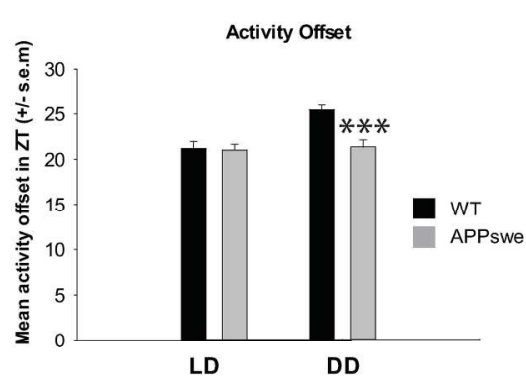

B

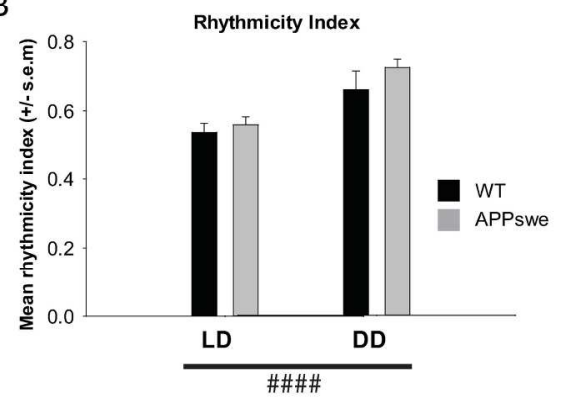

D

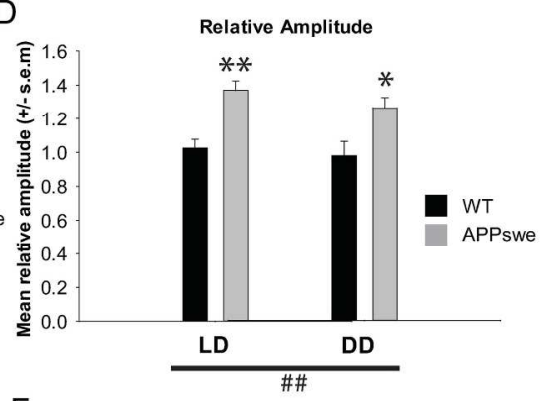

F

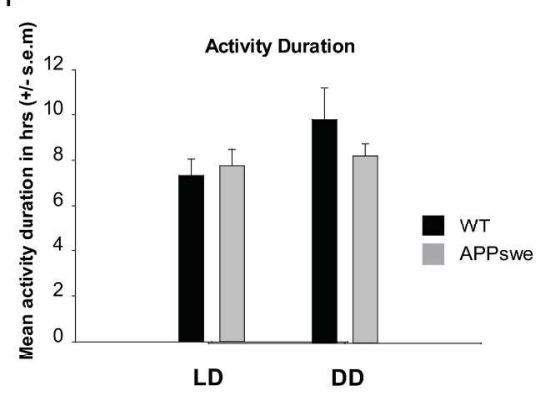

Figure 3: Effect of genotype on (A) Robustness, (B) Rhythmicity index (C) Acrophase (D) relative amplitude $(E)$ activity offset $(F)$ activity duration in LD and DD conditions. * $p<0.05 * * p<0.01 * * * P<0.001$ versus

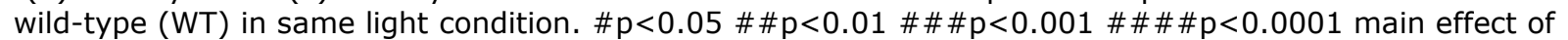
light condition i.e. Light-dark (LD) Vs constant darkness (DD).

Figure 3

$217 \times 240 \mathrm{~mm}(300 \times 300$ DPI $)$ 
Figure 4

A

Wild Type

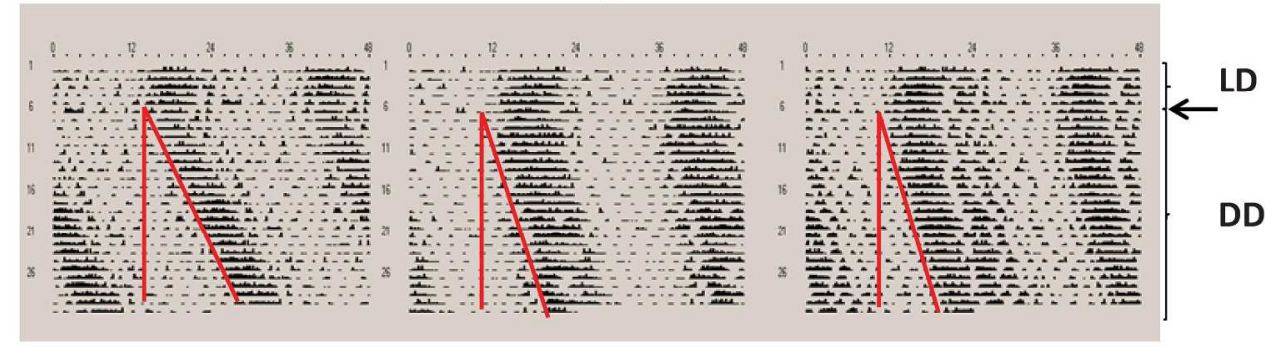

APPSwe

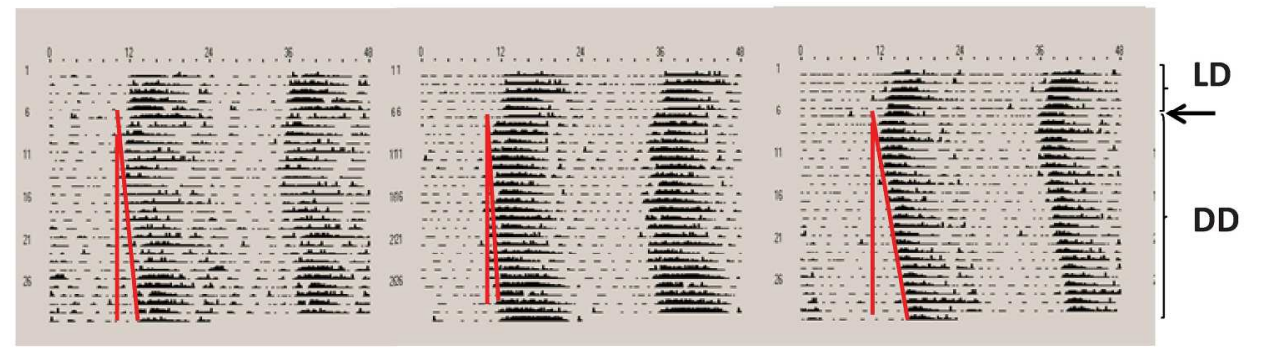

B

Mean Period Length

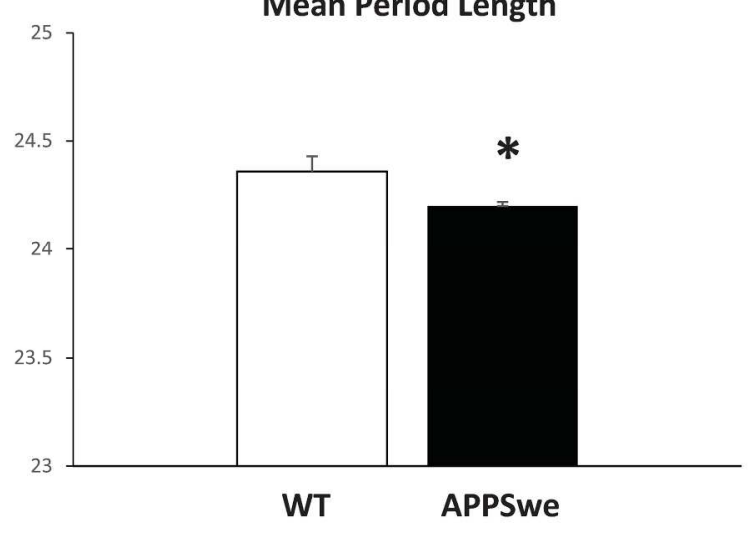

Figure 4: (A) Double - plotted actograms illustrating delay in onset of active phase in WT moved to DD but not in APPSwe/PS1dE9 mice (red lines indicate line fitting to activity onset). (B) mean period length (+/standard error of the mean) in DD.

Figure 4

$226 \times 279 \mathrm{~mm}(300 \times 300$ DPI $)$ 
Figure 5
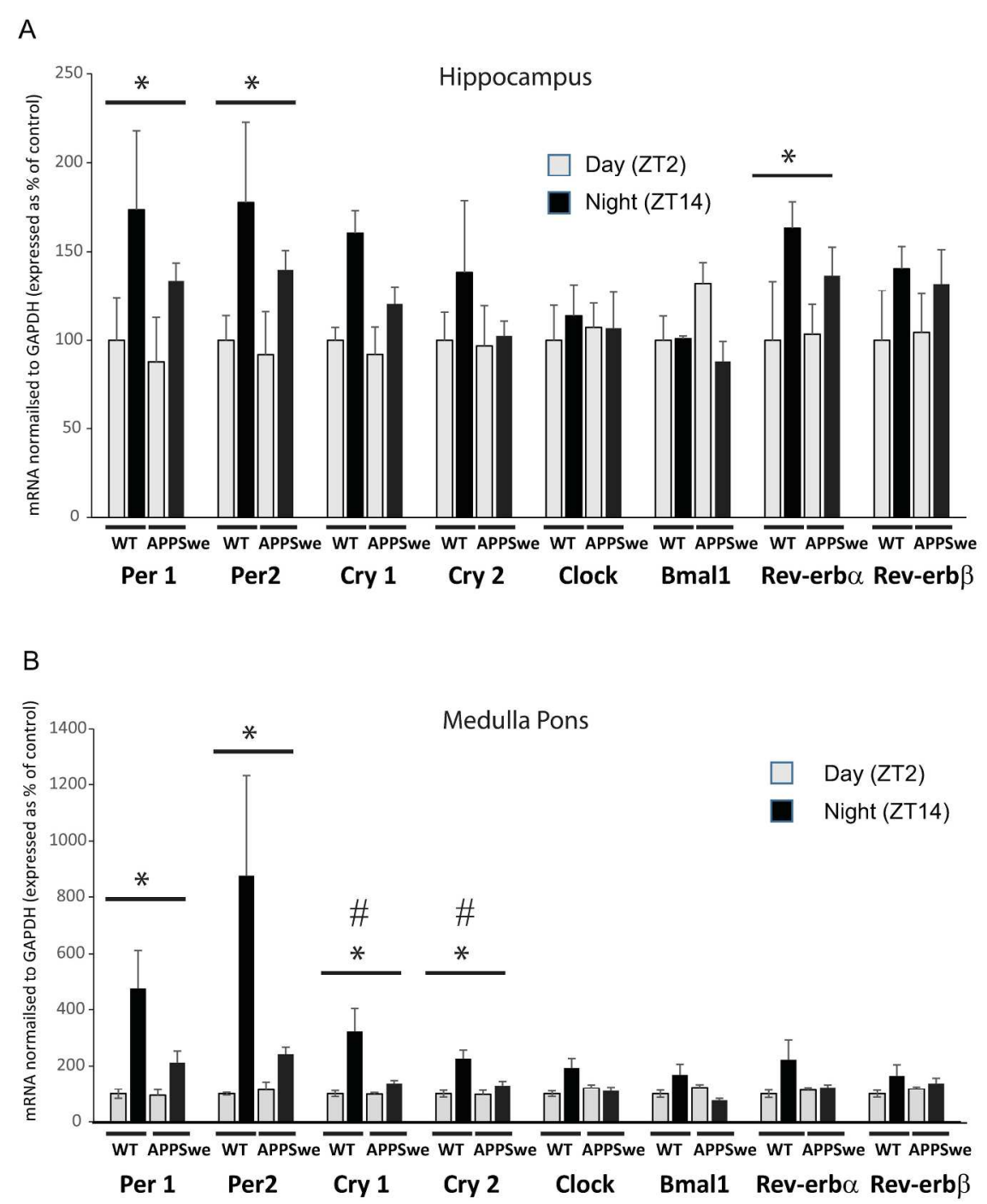

Figure 5: Day(ZT2)/night (ZT14) expression of core clock genes in the hippocampus (A) and medulla/pons (B) WT/ZT2 ( $n=3)$, WT/ZT14 $(n=3)$, APPSwe/PS1dE9/ZT2 $(n=4)$, APPSwe/PS1dE9/ZT14 $(n=4)$. Values shown are mean (biological replicates) \pm S.E with WT/ZT 2 normalized to $100 \%$. * indicates a significant overall effect of ZT (day Vs night) $p<0.05$, ANOVA). \#indicates a significant genotype $X$ ZT interaction $(p<0.05$ ANOVA).

Figure 5

$236 \times 265 \mathrm{~mm}(300 \times 300$ DPI $)$ 